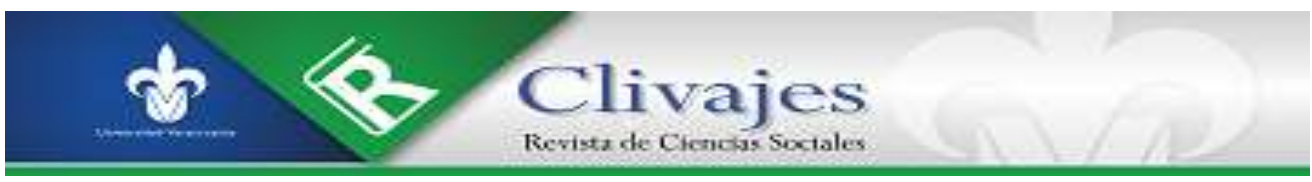

Sebastián Barros

LO POLÍTICO Y LOS PROCESOS DE IDENTIFICACIÓN

Clivajes. Revista de Ciencias Sociales. Año VII, número 13, enero-junio 2020, pp. 1-26.

https://clivajes.uv.mx/index.php/Clivajes/editor/proofGalley/2646/4459

Instituto de Investigaciones Histórico-Sociales, Universidad Veracruzana

Clivajes. Revista de Ciencias Sociales/ISSN: 2395-9495/IIH-S, UV/Xalapa, Veracruz, México

Recibido: 27/11/2019

Aceptado: 10/12/2019

Dictaminado: $17 / 03 / 2020$

Clivajes. Revista de Ciencias Sociales (ISSN: 2395-9495), Año VII, Núm. 13, enero-junio, 2020 


\section{LO POLÍTICO \\ Y LOS PROCESOS DE IDENTIFICACIÓN}

\section{Sebastián Barros*}

\section{Resumen}

El objetivo de este artículo es problematizar la manera en que la emergencia de demandas y su inscripción de un nuevo espacio de representación pueden dislocar el carácter instituyente de la política. En primer lugar, plantea que lo político opera sobre los límites del demos, expandiendo o restringiendo las diferencias, contadas como diferencias significativas en la comunidad. En segundo lugar, argumenta que esa cuenta se estructura a través de la asignación de ciertas capacidades sensibles a las diferencias que pueden significar un cambio respecto a la definición de lo común de la comunidad. En tercer lugar, el artículo señala que ese reparto de lo sensible está vinculado a un sujeto que puede hablar y ser escuchado en tanto portador de una palabra legítima, una diferencia que puede decir la verdad a través de prácticas parresiastas. En un contexto en el que todo el mundo puede hablar, porque la institucionalidad democrática así lo determina, aparece el riesgo de la mala parrhesía y que se pierda la oportunidad de identificar la palabra veraz, dispersa en la masa.

Palabras clave: Identidades, Estética, Parrhesía

\section{INTRODUCCIÓN}

Lefort (1988) señala que "la palabra 'política' nos pone en presencia de una ambigüedad que hay que resolver para saber de qué se habla" (p. 15). Una de las muestras de esta ambigüedad es el "hecho de elegir decir lo político y la política" (p. 15), elección que adquiere relevancia en tanto en ella se juega la delimitación de un campo. En el caso de la política, pensada "bajo la apariencia de una evidencia" (p. 16), se distinguiría de otras esferas de lo social, como la cultura, la religión, la estética, etc. Distinto es el caso de lo político, que no puede ser definido por oposición a otros campos. La pregunta por la delimitación del campo denominado político, para Lefort (1988), implica un momento instituyente que designa "los principios generadores de la sociedad o, por decir mejor, a las diversas formas de sociedad" (p. 18), con lo cual es muy difícil -prosigue nuestro autor- señalar algún tipo de actividad que suponga la coexistencia humana y no pueda encuadrarse, sea en la identificación de su origen o en el seguimiento de su desarrollo,

\footnotetext{
* Profesor-investigador en el Instituto de Estudios Sociales y Políticos de la Patagonia. Universidad Nacional de la Patagonia-CONICET, Argentina. Es Phd in Govermment - Ideology and Discourse Analysis Programme, MA in Political Theory (University of Essex) y licenciado en Ciencia Política (Universidad de Buenos Aires).
} 
dentro de esos límites de lo político. Las sociedades, de este modo, se distinguirían por "una cierta puesta en forma de la coexistencia humana" que no se deja localizar fácilmente, porque "la noción misma de sociedad contiene ya la referencia de su definición política" (p. 18). Una comunidad no existe, sino en su forma política. Ese momento instituyente de puesta en forma implica, a su vez, una puesta en sentido, el establecimiento de las condiciones de su inteligibilidad como forma, y una puesta en escena, una quasirepresentación de sí misma (pp. 20-21). Hay, entonces, una dimensión originaria de lo social que coincide con su forma política.

Esta puesta en forma presenta un problema para la ciencia política. Lefort (1988) menciona las limitaciones del análisis de las relaciones de fuerza entre clases determinadas por un modo de producción y de las inclinaciones funcionalistas, en boga, en la disciplina política de su tiempo. Sin embargo, la tematización lefortiana de lo político permitiría extender este comentario crítico a las vertientes contemporáneas institucionalistas, a la economía política y a aquellas que se detienen en la acción racional individual. En estos casos, desde la perspectiva del autor, no se plantea el interrogante sobre la "interiorización de los imperativos de la política llevada a cabo por los agentes sociales" (p. 23). Esta interiorización de imperativos, hecha carne en lo social, propicia que quienes intentamos dar explicaciones sobre los procesos que dispara nuestra coexistencia no podamos dejar de preguntarnos:

por qué y cómo pueden estabilizarse estas relaciones en una configuración dada, de tal manera que la fuerza dominante no necesite ya ejercerse manifiestamente; ... por qué y cómo estas relaciones escapan al conocimiento de los actores; por qué y cómo se hacen pasar por legítimas o conformes a la naturaleza de las cosas" (Lefort, 1988, p. 22).

La respuesta que propone Lefort es la de un pensamiento:

... sensible a una elaboración de la coexistencia que hace al sentido, producto de los puntos de referencia de lo verdadero y lo falso, de lo justo y lo injusto, de lo imaginario y lo real, que instaura los horizontes de una experiencia de las relaciones del hombre con el hombre y con el mundo (1988, p. 24).

De este modo, un acercamiento en términos de una "ciencia de la política" y sus evidencias no habilitará la operación de conocimiento que permite reconocer el criterio de lo que es político. La ciencia política, según Lefort (1988) no es la disciplina que 
permite precisar "el singular poder para aprehender una dimensión simbólica de lo político" (p. 13).

Este texto sugiere que, teniendo en cuenta la problematización lefortiana, el análisis político de los procesos identitarios brinda la posibilidad de precisar el carácter de lo político como momento instituyente. ${ }^{1}$ En primer lugar, vale aclarar que el análisis político de los procesos identitarios parte de una mirada sobre lo político teñida por las discusiones que propone Lefort (1990). La idea de la democracia como un régimen en el cual el lugar del poder es un lugar vacío (p. 190) constituye uno de los presupuestos que el enfoque asume en su periplo posestructuralista: en tanto el lugar del poder ya no se encarna en el cuerpo del monarca, el momento instituyente será contingente y dependerá de una particularidad que pueda circunstancialmente ocuparlo. En segundo lugar, el análisis político de los procesos identitarios no se restringe a la discusión de los problemas de una filosofía política ontológicamente distinta de una ciencia de la política. Los estudios identitarios toman los presupuestos ontológicos, pero para llevar adelante explicaciones precisas de las dinámicas que adquiere la coexistencia humana. En otras palabras, el análisis político de los procesos identitarios intenta responder a los interrogantes que el mismo Lefort (1988) planteaba a las ciencias sociales: ¿cómo dicho lugar vacío es ocupado contingentemente por particularidades que dan un contenido específico al momento instituyente? y ¿qué efectos tiene sobre la forma que adquiere la coexistencia el carácter de esas particularidades que dan sentido a la forma a través de una quasi-representación de sí misma? (p. 22).

Estos dos interrogantes nos permiten esbozar sendas cuestiones para comenzar a dilucidar la manera en que los análisis identitarios pueden problematizar el momento instituyente. Por un lado, la cuestión de la emergencia de la diferencia, es decir, la pregunta sobre esas particularidades que se disputan la inteligibilidad misma de la forma, a través de una puesta en escena y una puesta en sentido. Y, por el otro, la pregunta sobre la forma misma que se desprenderá del resultado parcial y contingente de esa disputa. El objetivo del texto es problematizar la manera en que la emergencia de demandas puede dislocar el carácter instituyente que tiene la política. Los procesos de desidentificación corren en paralelo a procesos de subjetivación. El surgimiento de una demanda, la emergencia de una nueva diferencia, conlleva una desidentificación que fuerza la necesidad de una nueva identificación. En ese impasse, entre la desidentificación y la inscripción de la nueva diferencia en un espacio de representación, se produce la

\footnotetext{
${ }^{1}$ Para una revisión del análisis político de los procesos de identificación, se sugiere: Aboy Carles (2001); Buenfil Burgos y Navarrete Cazales (2011); Padilla y Ruiz del Ferrier (2015).
} 
subjetivación. La idea de “proceso de identificación” pretende dar cuenta de ese conjunto de procesos que se ponen en juego en la desidentificación y la subjetivación. El estudio de este proceso de identificación es - creo- relevante para precisar el carácter de lo político como momento instituyente. ${ }^{2}$ El texto comienza, entonces, con la revisión de dos cuestiones. Una, la cuestión de la emergencia de la diferencia y los procesos de desidentificación $^{3}$ que supone, y otra, la cuestión de la disputa por la configuración del espacio en que se inscriben.

\section{SOBRE LA DIFERENCIA}

La emergencia de diferencias no ha sido un problema detenidamente tratado por las teorizaciones que sustentan a los estudios identitarios. Si bien existen reconstrucciones genealógicas o históricas que ponen su atención sobre identificaciones y buscan pacientemente desmenuzar los procesos de constitución de la diferencia, no ha habido una conceptualización de los procesos que dan lugar a la emergencia y estabilización de la diferencia en tanto diferencia. En el caso del análisis político del discurso de corte gramsciano de Ernesto Laclau y Chantal Mouffe (1985), por ejemplo, la propuesta de tomar a la demanda como unidad básica de análisis (Laclau, 2005) se sostiene sobre la presunción de que una demanda tiene un carácter crítico respecto de una situación determinada. Lo que dispara la aparición de una diferencia y su identificación como demanda es la necesidad de dar respuesta a una falla constitutiva de la estructuración de la vida social, ya que "en tanto que idea regulativa la coherencia de la estructura debe ser puesta en cuestión” (Laclau, 1990, p. 46). El problema es que esto deja las demandas como siempre-ya diferencias, irrupciones dislocantes de una forma instituida que, por otra parte, siempre es cuestionada y resistida.

Ahora bien, esto conlleva una manera específica de entender el momento instituyente de la puesta en forma. Porque si tomamos a la demanda como siempre-ya diferencia, ese momento político de la institución deberá entenderse como la actividad que administra la relación entre diferencias. Lo político se transforma, así, en la gestión de la diversidad de las diferencias. Esta manera de entender lo político tiene una tradición

\footnotetext{
${ }^{2}$ Debo y agradezco esta aclaración sobre los objetivos del texto y sobre la distinción entre proceso de identificación y subjetivación al sugerente comentario crítico de una de las evaluaciones académicas anónimas recibidas.

${ }^{3}$ Utilizo la idea de desidentificación porque no existe un "momento cero" de la identificación. Todo proceso de identificación supone desidentificarse con algo y viceversa.
} 
en la cual se encarna, y asume que la diferencia siempre surge a partir de la percepción de una carencia por parte de un elemento al interior de cierto espacio de representación.

Las maneras de entender la diferencia para dar cuenta de la existencia de particularidades políticas constituyen un relato bastante particular en la teoría política occidental moderna. ${ }^{4}$ En ella, la diferencia aparece siempre como efecto de las carencias que se aprecian en el contacto y el compartir con otros. Los distintos relatos asumen la existencia de diferencias anteriores a la vida comunitaria (Hobbes) o que emergen, como mínimo, en el momento mismo en que se gesta algo común (Rousseau). El sujeto hobbesiano tiene conciencia de la igualdad en mente, cuerpo y esperanza; y es a partir de esa conciencia de la igualdad, que se enfrenta a las diferentes formas de entender el derecho al mundo y la pluralidad de voces que (des)organizan el estado natural. En Rousseau, el contacto con un otro es lo que permite descubrir la propia singularidad. Ese otro naturalmente más veloz, más o menos fuerte o bello es el origen de las desigualdades naturales que se irán transformando en convencionales, a medida que se tome conciencia de la diferencia que implica la carencia de velocidad, fortaleza o belleza. Marx no es distinto en este sentido ni a Hobbes ni a Rousseau. La conciencia de la particularidad es fruto de la división social que se produce en la relación con la naturaleza como recurso. La conciencia de la diferencia y la particularidad se desprenden de la estructuración de la vida material, entendida como el modo de relacionarse socialmente con la naturaleza a través del trabajo, y se representan como carencia de la generosidad que debía caracterizar a lo humano.

Una crítica a esta manera de entender la diferencia puede encontrarse en el trabajo de Pierre Clastres, autor caro, afectiva y teóricamente, a Lefort. Este antropólogo político mostró una manera alternativa de pensar la diferencia, que luego tendría impacto sobre el momento de la puesta en forma de lo social. Clastres (2008) señaló que la idea de vincular automáticamente la diferencia a una carencia no es la única ni necesaria posibilidad para pensar su origen o emergencia. En sociedades donde no hay posibilidades para la acumulación y donde no existe la oportunidad para que la diferencia aproveche puntos flacos de otra diferencia, lo político tendrá un carácter distinto. Como bien señala Lefort (1988), muchos comentarios sobre la obra de Clastres la describen como análisis de una sociedad indivisa (de hecho, así la denomina él por momentos). Sin

\footnotetext{
${ }^{4}$ Por ejemplo, además de la pregunta sobre la idea de demanda como unidad básica de análisis en la producción de Laclau, podrían plantearse preguntas como las siguientes: ¿cómo emergen las diferencias que participan de la posición original rawlsiana?; ¿cómo son pensadas las diferencias en el pluralismo discutido por la ciencia política en la producción de autores como Robert Dahl?; ¿cómo se entiende la emergencia de los sujetos racionales que forman parte de los procedimientos deliberativos habermasianos?; y un largo etcétera.
} 
embargo - dice--, Clastres escribe sobre sociedades que perciben la división, pero dirigen todos sus esfuerzos a evitarla. Más allá de que se puede estar en desacuerdo con el argumento clastresiano de las sociedades contra el Estado, lo relevante es que, en las sociedades que él estudia, la diferencia existe no sólo entre una multiplicidad de comunidades, sino también intracomunitariamente (en la diferencia sexual del trabajo, la aceptación de la homosexualidad, la singularidad de la jefatura, etc.), cuestión que volverá a aparecer en este texto al momento de revisar el aporte de la estética-política rancièriana.

Más allá de la complejidad de los interrogantes que plantea Clastres a la teoría y filosofía políticas (Abensour, 2007; Loraux, 2007; Lefort, 2007; Moyn, 2013; Tible, 2014), el aporte que nos interesa destacar aquí es la emergencia de las diferencias. Para Clastres (2008), lo político no se limita a una actividad que pone en común siempre-ya diferencias, sino que es la matriz de toda diferencia (p. 23), a través de la guerra y la exogamia como formas de alianza. Lo político opera, así, sobre los límites del demos, expandiéndolos o restringiéndolos, según suma o resta elementos que adquieren o pierden el carácter de diferencias en la vida comunitaria. ${ }^{5}$

Por una parte, la política está en la exogamia. Para Clastres (2008), ésta no tiene como función asegurar la prohibición del incesto, sino que, al obligar a contraer matrimonio fuera de la comunidad de origen, "la exogamia local encuentra su sentido en su función: es el medio de alianza política" (p. 57). La exogamia supone, entonces, la existencia de "estructuras polidémicas" (p. 58), con lo cual la presencia de una pluralidad de demos no es pensada como resultado de la hostilidad o el temor mutuo entre particularidades diferenciales, sino como producto de fuerzas unificadoras que agrupan a los pueblos "en conjuntos de dimensiones variables". Esas fuerzas unificadoras tampoco deben ser pensadas meramente en términos biológicos, ya que el parentesco y el linaje deben también ser abordados en relación con la fuerza social, material y afectiva que tienen sobre los vínculos entre las personas (Ramos y Delrío, 2008, p. 153). La exogamia, para Clastres (2009), no tiene entonces una función biológica o cultural, sino política. El matrimonio con alguien extraño a la propia comunidad extiende los límites de ese "espacio exclusivo de ejercicio de los derechos comunitarios" (p. 44) que es el demos. El conflicto en un matrimonio produce el efecto contrario, restringiendo esos límites.

\footnotetext{
${ }^{5}$ Estos argumentos derivan de ideas que ya he presentado en Barros, 2013.
} 
Por otra parte, aún más importante en términos políticos es la guerra. La guerra, en tanto voluntad de afirmar su diferencia frente a otros, opera políticamente como rasgo estructural de las sociedades primitivas. A su vez, esa voluntad es el resultado de una lógica sociológica que asume que la sociedad primitiva, como toda unidad diferencial, necesita de la alteridad para pensarse como totalidad. Más allá de los diversos contenidos específicos que pueda tener cada situación particular de guerra o de alianza, siempre permanece este dispositivo encarnado en la tensión entre alianza y guerra que implica la política. En esa tensión la guerra tiene un carácter constitutivo, porque la alianza política es su corolario: "el estado de guerra [es] permanente en tanto conserva a todas las comunidades en su diferencia respectiva" (p. 69). En el argumento de Clastres, la guerra es lo que permitía el despliegue de la sociatividad, el libre juego del ser político de las sociedades primitivas; esto significa que el vínculo con la alteridad es siempre político, en tanto su existencia se plantea en el movimiento mismo que lo excluye. En el caso de las sociedades primitivas, este movimiento excluía de un territorio, de un espacio representado como propio y que Clastres describió como espacio exclusivo de ejercicio de derechos comunitarios, como un demos. ${ }^{6}$

Al analizar la estructuralidad de la exogamia y la guerra, la antropología política de Clastres (2009) puso la mirada -lefortianamente podríamos decir-sobre el momento de la institución de los límites del demos. Para Clastres, es lo político, en tanto actividad que opera sobre los límites de la vida comunitaria, lo que constituye las diferencias legítimas y no la existencia de diferencias, la que hace necesario lo político.

La lectura clastresiana del momento instituyente de la puesta en forma de lo social supone una puesta en escena y una puesta en sentido que procede sobre los límites de una comunidad. La forma expansiva o restrictiva de sus límites externos, la representación de sus divisiones internas y el significado que éstas adquieren hacen el momento instituyente en Clastres (2009), quien se distancia así de la noción de lo político como mera administración de las relaciones entre siempre-ya diferencias. Obviamente que dicho rol de la política, la gestión de las relaciones diferenciales, no deja de existir. Sin embargo, no debemos perder de vista que, para Clastres, la puesta en forma, en sentido y en escena no es solamente la representación simbólica de una división constitutiva, sino también la matriz que define cuáles serán las diferencias que participarán en dicha representación.

Ahora bien, esta imagen de límites en expansión o retracción, que engullen o expulsan diferencias, no es del todo justa con Clastres. Su conclusión sobre la política

\footnotetext{
${ }^{6}$ Esto implica necesariamente su opuesto, esto es, que la política, en tanto actividad, constituye diferencias ilegítimas que no podrán ejercer plenamente esos derechos comunitarios.
} 
como matriz de toda diferencia implica la incorporación o resta de diferencias significativas. ¿Qué implica para los estudios identitarios el hecho de que la política sea pensada como matriz de toda diferencia significativa? Implica que los procesos de identificación y desidentificación se relacionan con los efectos de la expansión o restricción de los límites comunitarios. Los desplazamientos de los límites transforman esos elementos individuales en diferencias significativas al interior del demos o, en caso contrario, cuando esos límites se restringen esas diferencias pierden su carácter significativo. Esta transformación se sostiene en un proceso identificatorio, bellamente descrito por Lefort (1988) cuando afirma que estas diferencias configuran una división interna a lo social: "en la medida en que sus términos son determinados no sólo por sus relaciones, sino que lo son por su común inscripción en el mismo espacio y testimonian una común sensibilidad ante esa inscripción" (p. 19).

El problema que nos deja ver Clastres (2009), la inscripción de nuevas diferencias significativas (Norval, 2012; Kalyvas, 2008), es vinculada, así, por Lefort (1988), a una “común sensibilidad”. Esto nos pone en el plano de lo estético-político, no como un estudio sobre lo bello en las identificaciones, sino como manera sensible de entender la puesta en forma (Plot, 2015, p. 38).

\section{SOBRE LA ESTÉTICA}

De este modo, lo político en tanto puesta en forma se encarama sobre una común sensibilidad hacia la inscripción de diferencias en una comunidad. Es más, podría decirse que en la base del pensamiento anti-totalitario lefortiano se encuentra precisamente dicha sensibilidad hacia la pluralidad de diferencias como condición para una vida democrática. Por ejemplo, al referirse a las iniciativas heterogéneas de una pluralidad de "minorías o de determinadas categorías de la población” que reclaman derechos, Lefort (1990) argumenta que tanto aquello que les da identidad particular como aquello que las aglutina en un proyecto de alcance más general, es el "descubrirse" diferentes o semejantes a las demás. No es el frío interés aquello que las une, sino la combinación de "la noción de una legitimidad y la representación de una particularidad" que se sostiene en "la eficacia simbólica de la noción de derechos” (p. 30). El reconocimiento del carácter simbólico del poder, la delimitación de una esfera de lo político debe coincidir con un "modo nuevo de legitimación” de las relaciones sociales (Lefort, 1990, p. 42), es decir que la inscripción de las diferencias y el modo de la legitimación de sus relaciones están atravesados por una "común sensibilidad". 
¿Qué supone esa sensibilidad? Jacques Rancière (2014) remite tal sensibilidad a la relación entre lo visible y lo invisible, entre lo escuchable y lo no escuchable. Cierta capacidad sensible es aquello que nos hace ver o no ver, nos hace escuchar o no escuchar, ${ }^{7}$ con lo cual implica también la existencia de un sujeto sensible, capaz de ver, hablar y escuchar; en palabras del autor: "La política se refiere a lo que vemos y a lo que podemos decir, a quien tiene la competencia para ver y la cualidad para decir, a las propiedades de los espacios y los posibles del tiempo” (p. 20, cursivas agregadas). De este modo, para Rancière, la política es siempre un registro de lo estético-político, lo cual enmarca una distribución de lo sensible que delimita cuanto se puede pensar como objeto y cuanto define al sujeto que puede pensarlo. Para Rancière, la división social es una división sensible.

Ahora bien, así como este punto nos deja ver una coincidencia con Lefort (1990), nos permite destacar, además, una especificidad de la mirada de Rancière (2014), fundamental para los estudios de los procesos de identificación. La coincidencia, que para ambos autores es la inscripción de la división de lo social, significa un problema de legitimidad, pero a eso Rancière (2011) agregará - como antes insinuamos-que también constituye una división del carácter de las diferencias coexistentes. En sus palabras: "la legitimidad de la dominación ha reposado siempre sobre la evidencia de una división sensible entre humanidades diferentes" (p. 43). Lo estético-político o lo político-estético es lo que permitirá precisar la dislocación de ese reposo en un movimiento que conjuga el reclamo por la igualdad para juzgar y actuar por parte de esas diferencias. La división entre humanidades diferentes opera sobre el entendimiento de las reglas del arte y de la política, sobre el sujeto del goce estético, sobre el espacio común, que recorta lo político, y sobre la cualidad de quien puede habitar ese espacio común. ${ }^{8} \mathrm{Si}$ la configuración del espacio común implica una distribución de lo sensible y éste, a su vez, supone una división de lo social entre humanidades diferentes, lo estético-político o político-estético llevará intrínseco el conflicto sobre la existencia misma de ese espacio.

En suma, el origen de las demandas no se ubica en un espacio común preconstituido, sino que la puesta en forma expande o restringe conflictivamente los límites del demos, de manera tal que los elementos presentes se van transformando en diferencias

\footnotetext{
${ }^{7}$ Remitir a la escucha en la política presupone que hay también una palabra a ser escuchada, pero desde nuestra perspectiva resaltar la escucha es relevante, porque, si bien para Rancière (2014) en la política emerge un sujeto que reclama una voz que enuncie lo común y no solamente lance un grito de necesidad o dolor, el efecto sobre la vida comunitaria se encuentra en las reverberaciones de la escucha de esa voz, antes que en la mera enunciación.

${ }^{8} \mathrm{Si}$ sumamos el argumento pedagógico de Rancière (2003) también lo hará sobre la jerarquía entre el maestro y el niño, el no-pueblo y el hombre de pueblo, una inteligencia superior y el sujeto de la sensación (p. 15).
} 
significativas o bien, por lo contrario, dejan de serlo; a su vez, la significatividad de dichas diferencias depende de una división sensible entre ellas, de:

un recorte de los tiempos y de los espacios, de lo visible y de lo invisible, de la palabra y del ruido que define a la vez el lugar y lo que está en juego en la política como forma de experiencia. La política se refiere a lo que vemos y a lo que podemos decir, a quien tiene la competencia para ver y la cualidad para decir, a las propiedades de los espacios y los posibles del tiempo (Rancière, 2011, p. 20).

De este modo, regresamos a nuestro punto inicial sobre la emergencia de la diferencia, los procesos de (des)identificación que ésta supone y la cuestión de la disputa por la configuración del espacio en que ambos se inscriben. Por un lado, la sensibilidad ante la inscripción de diferencias presume un sujeto para quien la puesta en forma es inteligible (tiene sentido) y está inmerso en la auto-representación de la forma comunitaria (puesta en escena). En otras palabras, lo político implica una identificación sensible de los sujetos con la forma, el sentido y la representación de su coexistencia. Por otro lado, esa sensibilidad no está parejamente repartida, como veremos en un momento, en tanto es asignada al sujeto por medio de un reparto de lo sensible, potencialmente desestabilizado por una presunción de igualdad.

La división sensible, de algún modo, es el respaldo en el que se apoya la puesta en forma, sobre todo en las sociedades contemporáneas en las que Rancière (2011) identifica un giro ético en la estética y en la política (pp. 133-ss). La ética, para él, es “el pensamiento que establece la coincidencia entre un entorno, una manera de ser y un principio de acción" (p. 134); coincidencia que se acerca a la definición de policía, tan difundida en las lecturas de Rancière, contracara de la política como desacuerdo (Rancière, 2006). Pero no podemos dejar de señalar que es una coincidencia expuesta a los desplazamientos inestables de las diferencias significativas en la distribución, que atribuye "facultades sensibles diferentes" a aquellos que se sitúan en lugares distintos (Rancière, 2011, p. 22).

Estos desplazamientos no se producen solamente a nivel de los límites del demos. Lo que nos deja ver Rancière, respecto de los procesos identificatorios. es que esos desplazamientos o arrancamientos se producen al interior de los espacios de la vida comunitaria y que en ellos se pone en juego la significatividad de las diferencias. Ellos dan lugar a la emergencia de diferencias que, en su reclamo por esa significatividad, se presentan como seres con facultades sensibles al arte, a la palabra legítima o a la 
inteligencia. ${ }^{9}$ La emergencia de estas sensibilidades significativas tiene efectos relevantes - como dijimos- para los estudios identitarios. En tanto proceso de desidentificación (Rancière, 1996, p. 53), la aparición de nuevas diferencias dispara una partición de la vida comunitaria que desarregla la distribución de lugares sociales. Para Rancière, este desarreglo tiene un carácter especial, porque es disparado por un sujeto que se presenta como víctima de un daño: la propia comunidad y quienes la gobiernan impiden el reconocimiento de esas voces como sensibilidades iguales, con lo cual estos reclamos quedan sometidos a una paradoja, porque reclaman algo que tienen en tanto partes de la comunidad: el derecho a ser escuchados, como seres sensibles que pueden expresar una palabra significativa, pero de lo cual no pueden disfrutar en tanto víctimas (Rancière, 2004).

En definitiva, la emergencia de estas identificaciones transforma la comunidad en una comunidad dividida "respecto de sí misma" (Rancière, 2011, p. 140). Estas identificaciones desarman la coincidencia que haría de la comunidad una comunidad ética. Ellas plantean la aparición de un nuevo sujeto que desata el nudo entre entorno comunitario, manera de ser y principio de acción. En ese momento de apertura lefortianamente instituyente- se politiza la forma de la comunidad, se trastoca su puesta en sentido y escena. La comunidad cambia, pues se demuestra que la coincidencia entre entorno comunitario, el modo de ser legítimo que le corresponde y el principio de acción que lo guía son una ficción desnaturalizada (Rancière, 2019, p. 129). Este es el punto que sustenta la emergencia de esas identificaciones que reclaman para sí la legitimidad de ser diferencias significativas, diferencias que pretenden hacer una diferencia en la discusión sobre la forma, la autorrepresentación y el sentido de lo común.

La idea de diferencias que pretenden hacer una diferencia es -creemos- un aporte central que nos deja Rancière para el análisis político de los procesos identificatorios. Lo que aporta esta idea es que no toda unidad que coexiste en una sociedad puede ser identificada como diferencia significativa y legítima en la puesta en forma, escena y sentido que señala Lefort. Este punto nos ayuda a pensar cómo el análisis de los procesos identificatorios contribuye a precisar la idea de lo político, porque en la obra de Lefort este problema no es tematizado con la misma preocupación. Para él, la coexistencia se hace "carne" y en ella pervive la pluralidad de diferencias, pero no dirige su atención a la

\footnotetext{
${ }^{9}$ En consonancia, con los tres registros, a menudo entrelazados, de su trabajo teórico. Un registro estético, uno político y otro pedagógico; en los tres opera la presunción de igualdad como punto de partida de la reflexión y como disparador de la identificación.
} 
dinámica de inclusiones y exclusiones que se pueden poner en juego en esa “carne”. Rancière nos ayuda a ver que en esa carne se juega un juego no exento de exclusiones que, a su vez, son condición de posibilidad para la emergencia de nuevas diferencias significativas. Para Rancière, el momento instituyente de lo político es el instante en el que emerge la política como distorsión del reparto de lo sensible.

Ahora bien, Rancière tampoco nos dice mucho sobre este juego, más allá de las transformaciones que pueda sufrir la distribución de lo sensible y del paciente trabajo de archivo que realiza, por ejemplo, en La noche de los proletarios. Esta distribución cambia por trastocamiento de la cuenta de las partes, producido por la suspensión de la jerarquía entre las palabras y los cuerpos. Nuevas demandas que, a través de un proceso de desidentificación y, por lo tanto, de subjetivación, reclaman para sí la palabra legítima. Poco nos dice Rancière sobre el proceso de desidentificación mismo y de cuáles son sus efectos sobre la estructuración de la vida comunitaria. La comunidad será otra, gracias a parciales procesos emancipatorios, resultado de la erupción de la diferencia política, pero no podríamos decir mucho más. De alguna manera, se desarma la coincidencia entre el estado de la comunidad, el modo de ser del sujeto y el principio de acción que los guía, por la aparición de una parte hasta ese momento no contada, pero no tenemos mayores precisiones al respecto. Esto es importante para el análisis político de los procesos de identificación y la forma que adquiere el espacio comunitario. La precisión del análisis dependerá en parte de la lectura que hagamos de la dinámica específica que adquiere la diferencia cuando emerge y reclama significatividad (diferencias que pretenden hacer una diferencia) y los efectos que estos reclamos pueden tener sobre la forma más general que adquiere lo político como momento instituyente.

\section{LA LÓGICA PARRESIASTA}

Quien sí se detuvo a auscultar estos procesos fue Michel Foucault (2009) en el análisis de lo que denomina "juego de la política", con la firme convicción de distinguirlo de la idea de "lo político". En uno de sus últimos cursos, Foucault critica expresamente la distinción lefortiana (pp. 171-172). ${ }^{10}$ En este trabajo, no nos interesa detenernos en esta crítica, pero sí revisar cómo el análisis foucaulteano de la dinámica del juego de la política en la

\footnotetext{
${ }^{10}$ No es el caso de las referencias de Foucault a Clastres. En "Las redes del poder", Foucault (1999) menciona que encuentra en la obra del antropólogo "toda una nueva concepción del poder como tecnología, que intenta emanciparse del primado, del privilegio de la regla y la prohibición que, en el fondo, imperó sobre la etnología desde Durkheim hasta Lévi-Strauss" (p. 237).
} 
democracia nos puede brindar herramientas para precisar mejor el carácter instituyente de los procesos de desidentificación y sus efectos.

Como ya dijimos, los efectos de los procesos de desidentificación son distorsivos, es decir, las nuevas diferencias que reclama una palabra significativa distorsionan la distribución de lo sensible. Allí reside la política en la obra de Rancière y allí es donde Foucault (2009 y 2017) pondrá atención durante su lectura de una serie de textos clásicos en los que rastreará la emergencia de la diferencia significativa para el gobierno de la ciudad y de una dinámica específica de la democracia como forma de gobierno.

Foucault (2009) desprende de dicha lectura un principio relevante para pensar las dos cuestiones que nos interesa analizar: la idea de que un individuo se constituye como sujeto en la relación consigo mismo y con los demás (p. 58) y que esta constitución subjetiva se produce a través de lo que denominaremos lógica parresiasta. La parrhesía refiere un tipo de relación entre la persona que habla y lo que esa persona dice. Foucault rastreó las diferentes maneras en que aparece la parrhesía en una serie de tragedias griegas, donde surge como una práctica, una virtud, una técnica, una figura retórica, etc. ${ }^{11}$ La posibilidad de entenderla como una lógica decanta de la incidencia de la dinámica parresiasta sobre la configuración del espacio político mismo.

Cuando referimos una lógica, seguimos la definición y uso que hacen David Howarth y Jason Glynos (2007) cuando señalan que "la lógica de una práctica comprende las reglas o la gramática de una práctica como también las condiciones que hacen a la práctica tanto posible como vulnerable" (p. 136). En este trabajo Howarth y Glynos proponen tres tipos de lógica: social, política y fantasmática; ${ }^{12}$ la que nos interesa destacar aquí es la lógica política, la cual, siguiendo a Laclau y Mouffe (1985), se divide en lógica de la diferencia y de la equivalencia. Si la equivalencia y la diferencia son las gramáticas políticas que estructuran las relaciones entre diferencias, la parresiasta será la gramática que permite reconocer cuáles son las diferencias capaces de ser articuladas, diferencial o equivalencialmente. Si la equivalencia y la diferencia hacen al carácter, la intensidad y la extensión del vínculo entre diferencias, la parrhesía hace al carácter mismo de la diferencia como diferencia y a la configuración del espacio que posibilita el vínculo.

\footnotetext{
${ }^{11}$ No es interés de este trabajo revisar la lectura de Foucault sobre dichas tragedias, antes bien nos interesan las preguntas que puede despertar sobre el presente y quizás para imaginar otro futuro, antes que la certeza de su mirada sobre pasado.

${ }^{12}$ Como señala Mercedes Barros (2008), a través de esta tipología de lógicas, Howarth y Glynos (2007) buscan capturar "qué" caracteriza a una práctica o régimen, “cómo" se constituyó y "por qué" es de hecho posible, respondiendo así a las tres preguntas básicas de toda investigación social.
} 
En resumen, queremos argumentar aquí que la lógica parresiasta comprende la gramática que define la emergencia de diferencias significativas, como también las condiciones políticas que la hacen posible. Pero veamos primero la problematización que Foucault (2009) lleva adelante de la práctica parresiasta. Su análisis de la parrhesía política comienza con la descripción de ésta como bisagra entre la politeia y la dynasteia, es decir, la parrhesía es una lógica del ajuste entre los problemas que corresponden a la ley y la constitución, y aquellos que corresponden a la dinámica agonística para lograr ascendiente. El problema de la política como experiencia: "La politeia define y garantiza el lugar de la parrhesía. Pero ésta, el decir veraz del hombre político, es el elemento en virtud del cual va a asegurarse el juego conveniente de la política [la dynasteia]” (p. 172).

La instancia ideal de este ajuste se produce cuando ese sujeto político habla con franqueza, despojado de todo uso retórico del lenguaje y dice la verdad. Decir la verdad no sugiere el acceso a una verdad que tiene un correlato empírico frente al cual puede ser evaluada, sino que supone la virtud de poder reconocer y expresar el ethos de la comunidad. La expresión de la verdad implica entonces correr un riesgo en tanto ella no será necesariamente lo que el resto de quienes coexisten en esa comunidad quieran escuchar. Así, quien logra expresar la verdad tiene el coraje para asumir un riesgo. En consecuencia, la parrhesía, como práctica, tiene una función crítica cuyo objetivo es señalar los puntos en los cuales esa comunidad se estaría desviando de su propio ethos. Quien señala ese desvío, además, lo hace deslindado de cualquier interés, lo hace porque es su deber hacerlo.

Si para Foucault (2009) "el individuo se constituye como sujeto en la relación consigo y en la relación con los otros” (p. 58), la posibilidad de ingresar en el juego de la parrhesía supone una transformación de ambas relaciones; esa subjetividad cambiará lo que estima acerca de sí y lo que estiman las demás. ${ }^{13}$ El impacto de una práctica parresiasta en la constitución de una subjetividad es indeterminado, no puede ser anticipado ni garantizado por arreglos institucionales. En un enunciado parresiástico, el compromiso de quien habla con lo que dice tiene un carácter disruptivo, "que genera una fractura y abre el riesgo" (Foucault, 2009, p. 79; Castro, 2014, p. 142). Esa fractura que abre el juego parresiástico, a su vez, afecta "el modo de ser del sujeto" (Foucault, 2009, p. 84). El compromiso que supone el enunciado parresiástico y el acto de su enunciación tienen un efecto retroactivo sobre la subjetividad. Foucault llama "dramática del

\footnotetext{
${ }^{13}$ Sobre la idea de estima y el tratamiento que se le da en estas discusiones remito a Barros, 2017.
} 
discurso" 14 a ese efecto en el modo de ser, que alude a cómo el acontecimiento de la enunciación afecta el ser de quien enuncia. La enunciación parresiasta tendrá entonces un efecto subjetivante, disruptivo e indeterminado. ${ }^{15}$

Con esto, la lógica parresiasta se emparienta con el reparto de lo sensible, vinculado ahora con la capacidad del sujeto para expresar una verdad comunitaria de forma relajada, franca, crítica y valiente. La enunciación parresiasta afecta el ser sensible de quien la enuncia: arranca al sujeto del lugar que ocupa y lo instituye como sujeto de verdad. La práctica parresiasta adquiere, así, un carácter muy relevante para los estudios identitarios, porque será central en la definición de las diferencias significativas que tendrían "acceso a una vida política entendida como posibilidad de opinar y contribuir, de tal modo, a la toma de decisiones colectivas" (Foucault, 2010, p. 51). La práctica parresiasta ajusta la condición que debe tener el sujeto para ser algo más que un mero espectador en ese proceso decisivo.

Para Foucault (2009), la gran pregunta de la parrhesía es “quién va a tomar la palabra, quién va a poder, de hecho, ejercer su influencia sobre la decisión de los otros, quién va a ser capaz de persuadir y quién, al pronunciar lo que a su juicio es la verdad, va a poder actuar así de guía de los otros?” (p. 198). En el análisis de la parrhesía política en una democracia, ésta significa "el derecho político a ejercer el hablar franco" (p. 165) y se distingue de la isegoría (igual derecho institucional a tomar la palabra) y de la isonomía (derecho a que la ley institucionalizada sea igual para todas las personas), porque no está mediada institucionalmente como las otras dos. Esto será importante cuando se piense la relación entre parrhesía y democracia, régimen que no podrá garantizar que prime la buena parrhesía.

En la caracterización de Foucault, la parrhesía política siempre opera en una democracia como una bisagra entre la institucionalidad que regla la vida comunitaria y la dinámica por la cual esa vida es gobernada. Aquélla ajusta la condición que debe tener el sujeto para ser algo más que un mero espectador de la vida comunitaria, estar entre quienes pueden decir la verdad de esa vida y contribuir a las decisiones colectivas. A su vez, este sujeto sostiene el ajuste en una práctica agonista que deja libertad para que los demás puedan hacer lo mismo, es decir que la preocupación por la parrhesía no es ajena a

\footnotetext{
${ }^{14}$ Habrá distintas formas de "dramática” - el profeta, el adivino, el filósofo, el sabio- y Foucault (2009, p. 85) analizará una posible "dramática política del discurso verdadero".

${ }^{15}$ Como puede desprenderse, lo que Foucault (2009) llama “dramática del discurso” cumple la misma función que la idea de gramática que Howarth y Glynos (2007) mencionan como elemento de las lógicas. La dramática, además, permite asociar la gramática a la afección sensible que el proceso de subjetivación implica para la emergencia de toda diferencia.
} 
la preocupación por la existencia de una pluralidad de diferencias que habitan la comunidad. En este caso, si Lefort tomaba la pluralidad como dada y Rancière mostraba que lo político distorsionaba esa pluralidad mediante una re-distribución de lo sensible, en Foucault la práctica parresiasta es ambivalente. El ajuste parresiasta puede ser un ajuste ideal, mediado por una buena parrhesía, pero también provocar un desajuste por la aparición de una mala parrhesía.

La instancia ideal del ajuste, la buena parrhesía, se produciría cuando el sujeto hablara con franqueza, despojado de todo uso retórico del lenguaje y dijera la verdad. Para eso, es imprescindible un contexto en el que las diferencias puedan expresarse libremente. Foucault (2010) señala, en este sentido, que la parrhesía tiene un vínculo circular con la democracia. No puede haber práctica de la parrhesía allí donde no hay igualdad ante la ley e igualdad para tomar la palabra, y sólo puede haber democracia cuando el gobierno surge de la persuasión y el logro de ascendiente a través del decir veraz. En la democracia, la parrhesía ajustará la dinámica entre las instituciones que le son propias con "los problemas específicos que son los de la política, la dynasteia, el ejercicio del juego político, y de este como campo de experiencia” (p. 171).

En relación con este juego político, Foucault señaló una tensión constitutiva de la democracia. La democracia como forma de gobierno se sostiene en la igualdad entre sus miembros para tomar la palabra y someterse a la ley, pero introduce una desigualdad: si esa comunidad va a ser gobernada, debe existir un desnivel entre quien gobierna y quien obedece. El carácter propio de la democracia se juega en esa tensión que no está presente en otras formas de gobierno. La tiranía, la oligarquía y la aristocracia no la sufren en tanto que quien gobierna no lo hace entre iguales.

La importancia de esta tensión se revela en su vínculo con la parrhesía. En una democracia, todo el mundo puede hablar, pero no todo el mundo puede decir la verdad. La verdad no puede estar repartida igualitariamente como los derechos. Si así fuera, no sería necesaria la persuasión que permite al sujeto lograr ascendiente y gobernar entre iguales, cuestión clave para la especificidad democrática. No habría nadie a quién persuadir. La afirmación de que todo el mundo puede hablar, pero no decir la verdad es muy importante para la teoría política. En general, las teorías de la política y, en particular, las teorías de la democracia intentan transferir la igualdad de derechos a una potencial o ideal igualdad en la dinámica de lo político. Y utilizamos "lo político" adrede en su acepción lefortiana: la igualdad de quienes portan derechos para poder identificarse de manera significativa con la puesta en forma, en escena y en sentido. Esa transferencia de la igualdad supone que, aunque sea lógicamente, se puede superar la tensión que constituye 
a la democracia como tal. Rancière (2011) sugiere una crítica similar cuando señala la dinámica particular entre consenso y exclusión (p. 140).

Esta idea, que hace a la dinámica de inclusiones y exclusiones, que se da en el juego político, también es importante para el análisis de los procesos de identificación, porque da cuenta del desajuste que supone la emergencia de diferencias novedosas en contextos democráticos. La democracia, atravesada por la lógica parresiasta, aloja una paradoja en la tensión entre su lógica institucional igualitaria y la escansión que introduce desigualdad en el juego de la política. Sobre esta paradoja se recostará la crítica a la democracia (Foucault, 2010, pp. 51-64), como una forma de gobierno que no provee mecanismos claros ni seguros para esa escansión, la cual habilitaría una distribución de lo sensible - para retomar el lenguaje rancièriano- y permitiría reconocer el discurso verdadero. El gobierno de los muchos no permite identificar la diferencia ética que habilitaría el reconocimiento de la verdad. En definitiva, la democracia, al habilitar que todo el mundo pueda hablar, no permite asegurar la diferencia entre prácticas y discursos que se presentan como parresiastas y pueden no serlo. ${ }^{16}$

La parrhesía, la bisagra que ajustaba la tensión democrática y permitía el reconocimiento del decir veraz, se transforma ahora en algo peligroso. El derecho a hablar se confunde con un presunto derecho a decir la verdad de una manera éticamente indiferenciada. En otras palabras, la parrhesía deja de ser la práctica para el buen ajuste del juego agonista de la política y se transforma en la mala parrhesía, en una práctica del desajuste que arrasa con la escansión ética que permitiría identificar el discurso verdadero. ${ }^{17}$ Por ello, tal y como argumenta Lefort, la democracia se transforma en una forma de gobierno marcada por la incertidumbre, por la idea escandalosa de que cualquiera puede gobernar, como lo expresa Rancière, ya que todo el mundo puede hablar y pretender decir la verdad. En última instancia, la democracia es la forma que asume el reconocimiento de la existencia de una pluralidad de logos (Foucault, 2017, p. 179).

Desde el punto de vista de las críticas a la democracia que analiza Foucault (2010), la mala parrhesía termina con el buen ajuste entre polietia y dynasteia; lo hace al desactivar la posibilidad de asegurar la identificación del discurso veraz. El problema son las instituciones de la democracia que dan libertad para que cualquiera diga cualquier cosa:

\footnotetext{
${ }^{16}$ En este registro operan las críticas a los populismos latinoamericanos, tanto del siglo XX como del XXI. Al respecto, puede verse Barros, 2017.

${ }^{17}$ El hecho de que cualquiera pueda hablar en un régimen donde es posible que los muchos se impongan sobre los mejores abre la puerta a la demagogia, a la palabra que solo dice lo que todo el mundo quiere escuchar. La democracia, el gobierno de los muchos, hace que el discurso veraz sea impotente.
} 
"Porque en ella no se puede distinguir el buen y el mal orador, el discurso que dice la verdad y es útil a la ciudad, del discurso que miente, adula y es perjudicial” (p. 58).

La democracia brinda, así, las condiciones para la emergencia de la mala parrhesía, porque la democracia, el gobierno de los muchos, hace que el discurso veraz sea impotente, es decir que la lógica parresiasta, además de definir el carácter de la diferencia como diferencia, configura la forma que adquiere el espacio que cobija sus posibilidades articulatorias.

En relación con estas posibilidades, Foucault (2010) señala cuatro principios "que fueron una matriz y un desafío permanente para el pensamiento político en el mundo occidental" (p. 61). Un primer principio cuantitativo, que distingue entre los muchos la masa- y los pocos - distinción capital en la democracia como forma de gobierno en la que se impone la mayoría-; un segundo, que hace a una escansión cualitativa entre mejores y peores, entre buenos y malos. Como los mejores lógicamente son pocos, el tercer principio se refiere a la correspondencia de la escansión ética con una distinción política: lo que es bueno para los pocos-mejores será bueno para la comunidad. Por lo contrario, lo que es bueno para los muchos-peores será malo para la comunidad. Finalmente, el cuarto principio es que lo verdadero en el orden del discurso político no puede decirse en la forma de la democracia entendida como derecho de todos a hablar.

Esto nos puede dar una idea de cómo funciona la lógica parresiasta. Si la lógica define el carácter de la diferencia articulable, operando sobre los límites del demos, también llevará adelante la escansión entre los lugares que cada una podrá ocupar en la vida comunitaria. A su vez, la lógica parresiasta define la forma de articulación que tendrá lugar entre esas diferencias.

Veamos ahora, muy brevemente y con espíritu casi ilustrativo, cómo opera la lógica parresiasta en el análisis político de los procesos de identificación. Obviamente, en los dos casos nos proponemos un ejercicio de carácter aclaratorio, antes que un análisis exhaustivo de los procesos identitarios en los que están inmersos.

Existen diversas maneras de procesar la distribución de lugares sociales en cuanto hace a la forma de representación de la comunidad. Aquí repasaremos dos ejemplos para tratar de mostrar la relevancia de pensar lo político en los términos que propusimos en este trabajo. Primero, tomaremos una afirmación de Juan Bautista Alberdi (1956) sobre la "república posible" en la que podremos ver la lógica parresiasta en su aspecto más restrictivo. Luego, revisaremos brevemente los comentarios de Aletta Norval (2006) sobre su experiencia de participación en las primeras elecciones democráticas en Sudáfrica. 
Al momento de evaluar la importancia de las elecciones libres para elegir autoridades en una Argentina que comenzaba a organizarse, Alberdi (1956) afirma lo siguiente:

La inteligencia y la fidelidad en el ejercicio de todo poder dependen de la calidad de las personas elegidas para su depósito; y la calidad de los elegidos tiene estrecha dependencia de la calidad de los electores. El sistema electoral es la llave del gobierno representativo. Elegir es discernir y deliberar. La ignorancia no discierne, busca un tribuno y toma un tirano. La miseria no delibera, se vende. Alejar el sufragio de manos de la ignorancia y de la indigencia es asegurar la pureza y acierto de su ejercicio (p. 100).

La fórmula general alberdiana era una combinación de "república abierta", en la cual ciertas libertades y derechos civiles eran respetados, y de una "república restringida", en la cual sólo los notables votaban. En la Argentina del siglo XIX, La razón de esta restricción al voto era clara para Alberdi, y su argumento planteaba que el progresivo ejercicio de las libertades civiles mejoraría "la calidad de los electores" y los calificaría para votar. En tanto forma de representación, la "república posible" suponía un espacio sostenido por las restricciones al voto y una partición de la vida comunitaria, articulada alrededor de la atribución jerarquizada de capacidades y sensibilidades distintas a las personas que la habitaban.

En esta breve referencia pueden encontrarse varios de los elementos que remarcamos a lo largo del trabajo. En primer lugar, el discurso alberdiano opera sobre los límites del demos, restando significatividad a una serie de diferencias abrumadas por la ignorancia y la miseria. El momento instituyente de lo político, la puesta en forma de lo social a través de una puesta en sentido y una puesta en escena, restringía las diferencias significativas mediante la negación de la sensibilidad que permitiría discernir y deliberar. Las instituciones de la república posible, el sistema electoral en este caso, era el principio de acción que producía la escansión ética necesaria para asegurar el acierto y el acceso a la pureza del discurso veraz. El peligro de una democracia liberada de las restricciones habilitaba el gobierno de los muchos-peores. La lógica parresiasta opera, así, sobre la sensibilidad que identifica a las diferencias significativas, sobre los límites del demos y sobre la forma del gobierno representativo. El tipo de operación que realiza tiene como resultado una sociedad claramente dividida.

Tomemos ahora el ejemplo sudafricano que nos brinda Norval (2006), en el que se pone en juego la expansión de los límites del demos. En este caso, la superación de momentos restrictivos da lugar a formas de representación que expanden los límites al 
modificarse las atribuciones de capacidad sensible para los distintos grupos. Tal es la descripción que hace Norval para el caso sudafricano. En las primeras elecciones democráticas en Sudáfrica luego del apartheid, las nuevas formas de identificación reclamaban la transformación de un espacio comunitario muy restrictivo. Norval muestra la emergencia de diferencias que, a través del reconocimiento de la multiplicidad de gramáticas políticas, tuvo como resultado la aparición de identificaciones democráticoliberales que estructuraron una forma de representación comunitaria particular. La articulación del reclamo igualitario de las identificaciones democráticas tuvo como resultado una práctica política orientada por el respeto a la diferencia y la multiplicidad, encarnado en un sujeto que asumía que todos los miembros de la comunidad estaban incluidos como en la capacidad de hablar y ser escuchados.

Luego de describir el carácter festivo de las primeras elecciones democráticas en ese país, con música mientras esperaba siete horas para votar, venta de refrescos, conversaciones animadas, etc., Norval (2006) explica que, en las largas colas para depositar el voto, lo que más llamó su atención fue la interacción entre negros y blancos que vivían y trabajaban en condiciones altamente desiguales:

Lo más notable, sin embargo, era la interacción entre quienes hacían fila para votar. Negros y blancos que vivían y trabajaban en las condiciones altamente desiguales de los suburbios "blancos", entablaban conversaciones y compartían una experiencia de enorme significación -como participantes iguales. Esta participación señalaba la suposición pública de una subjetividad democrática. ... Sin embargo, este día contribuyó a algo nuevo e importante, escapando a la mirada analítica con la que normalmente vemos a las elecciones y las actividades democráticas en general. Ocupar la posición de un sujeto democrático generó un contundente nuevo sentido de subjetividad en tanto iguales que dependía de su representación pública en un momento particular (p. 231).

Esa nueva subjetividad democrática dislocó la forma de representación del apartheid y se condensó en afirmaciones que asumían que todas las personas del país podían afirmar su estatus como sujetos iguales en la nueva democracia: “¡ahora somos todos demócratas!”, “¡ahora somos todos iguales!”, o “¡ahora somos todos humanos!”. La intolerancia a la diferencia fue reemplazada por una nueva apertura, por el sentimiento de tener "el derecho a ocupar una posición antes que la posición en sí misma" (Norval, 2006, p. 248).

Desde el punto de vista aquí propuesto, que pretende ir más allá del contenido literal de estas afirmaciones para entender mejor cuál es la forma de representación que implican, la tensión que Foucault encontraba en las tragedias griegas y que definiría a la 
lógica comunitaria de la polis, "todos pueden hablar, pero no todos pueden decir la verdad”, aparece como susceptible de ser lógicamente resuelta. En otras palabras, las identificaciones que Norval (2006) describe supondrían una forma de representación en la que se asume que todas las personas pueden hablar y todas pueden decir la verdad. En esta forma de representar la comunidad, existiría una diseminación igualitaria del discurso de verdad. Esto significa presuponer una forma de representación sin exclusiones en torno a la sensibilidad necesaria para compartir experiencias hasta ese momento inéditas, un reparto parejo del discurso de verdad. ${ }^{18}$ La lógica parresiasta, en este ejemplo, define nuevas diferencias sensibles al reconocimiento de la alteridad, amplía el demos desplazando sus límites y da forma a una sociedad en la que, en ese acto electoral, la división racial pasa a un segundo plano.

\section{REFLEXIONES FINALES}

En este artículo, nos preguntamos sobre el carácter del momento instituyente de lo político desde una reflexión vinculada con el análisis político de los procesos identificatorios. A través de la discusión de un autor cercano a Claude Lefort, como fue Pierre Clastres, de la obra de Jacques Rancière y de los últimos cursos de Michel Foucault en el Collège de France, llegamos a una serie de reflexiones que, a su vez, nos pueden servir como punto de partida para el trabajo teórico y empírico en el análisis identitario. En primer lugar, a partir de la obra de Clastres, pudimos complejizar el momento instituyente, como una instancia en la que se ponen en juego los límites del demos legítimo. Esto significa que la puesta en forma a la que se refiere Lefort define el carácter de las diferencias que coexisten en tanto diferencias significativas, es decir, diferencias que pueden hacer una diferencia en la estructuración de la comunidad, que pueden ocupar la primera fila en la puesta en escena y ser parte de la puesta en sentido. La significatividad de las diferencias, aquello que respalda la legitimidad de su pertenencia, está sostenida, a su vez, por la asignación política de cierta sensibilidad que permite la identificación del sujeto como parte de la comunidad.

Aquí reside la contribución de Rancière al análisis político de los procesos de identificación. En su trabajo se muestra la manera en que el registro de lo político es un registro de lo estético-político o lo político-estético. El momento instituyente es al mismo tiempo des-instituyente, en tanto que la política, como distorsión, provoca un

\footnotetext{
${ }^{18}$ Esto no significa que Norval no identifique ninguna restricción, sino que desde una perspectiva liberal se asume que la tensión puede ser lógicamente resuelta.
} 
quiebre y habilita una nueva distribución de lo sensible, con lo cual la idea de que lo político, como momento en que se modifican los límites del demos, se conjuga con transformaciones de las diferencias en torno a su capacidad sensible de ser parte de la comunidad y poder incorporar, al mismo tiempo, la fuerza dominante y el sentido de la coexistencia. A su vez, Rancière (2011) nos deja ver que ese momento instituyente es litigioso, producto siempre del conflicto por la asignación de esa sensibilidad necesaria para reconocer, legítimamente, qué es lo que organiza la coexistencia. La instancia que permite al sujeto reconocer el régimen bajo el cual se puede descubrir, evaluar y objetivar "cierta forma de aprehensión sensible" (p. 40) de la coexistencia. El desacuerdo tiene, así, como condición, la suspensión del poder de entendimiento que determina, cognitivamente, qué se puede conocer, decir y hacer, y del poder de la sensibilidad que permite saber qué se puede desear, y a qué aspirar en esa coexistencia.

Estos dos poderes, del entendimiento y de la sensibilidad, son lo que se conjuga en la idea de lógica parresiasta que tomamos de Foucault. Es una lógica en tanto nos deja ver las gramáticas y las condiciones de las prácticas que se juegan en el momento instituyente de lo político. Como lógica, operará sobre los límites del demos, definiendo las sensibilidades que podrán legítimamente tomar la palabra e intentar lograr ascendiente a través de la persuasión entre iguales. En este sentido, lo político, por más que Foucault se resistía a llamarlo así, es conflictivo, porque lleva consigo la tensión en el desnivel entre quien gobierna y quien obedece, a pesar de la igualdad ante la ley y para tomar la palabra. Tensión irresoluble en la democracia, marcada por la incertidumbre ética del gobierno de la mayoría. Esta escansión entre muchos y pocos puede ser reconocida por el entendimiento, ya que es una simple cuenta de las partes. Pero el momento ético, el momento en que el discurso veraz es reconocido a través de la parrhesía y logra imponerse como logos de esa comunidad, necesita una sensibilidad diferente al entendimiento. Es una sensibilidad que no tiene correlato empírico, que no se agota en su eficacia instrumental o en la mera satisfacción de una necesidad. Es la capacidad sensible de reconocer las posibilidades objetivas que se juegan en una determinada instancia social, de reconocer la idea de vida buena que se espera florezca en esa comunidad y el modo de ser franco, veraz, con coraje, a pesar de los riesgos y asumido como un deber.

Esta reflexión sobre lo político, desde el análisis de los procesos identificatorios, nos deja entonces con estos elementos que, al mismo tiempo, son conclusiones y puntos de partida. Lo político, como puesta en forma, opera cual matriz de la diferencia y, por lo tanto, sobre los límites del demos legítimo. En segundo lugar, esas diferencias se 
identifican como significativas para ser contadas como diferencias que deben poder hacer una diferencia en la dirección de la vida comunitaria, que deben poder hablar, pero también ser escuchadas, en tanto se disponen a decir la verdad. En otras palabras, son parte significativa de un reparto de lo sensible, que asigna capacidades y funciones. Por último, esa sensibilidad supone la capacidad del decir veraz, de un decir que está despojado de cualquier accesorio que distraiga del deber de decir la verdad. Pero cuando el demos se amplía y son los muchos quienes pretenden decir la verdad, esa vida comunitaria se trastoca. La igualdad institucional asegura que cualquiera puede hablar, pero no que pueda decir la verdad. Esa tensión, intrínseca e inerradicable de la democracia, es la que caracteriza a la lógica parresiasta.

\section{REFERENCIAS}

Abensour, M. (2007). El contra Hobbes de Pierre Clastres. En Abensour, M. (comp.), El espíritu de las leyes salvajes: Pierre Clastres o una nueva antropología política (pp. 189228). Buenos Aires: Del Sol.

Aboy Carles, G. (2001). Las dos fronteras de la democracia argentina. La reformulación de las identidades políticas de Alfonsín a Menem. Rosario: Homo Sapiens Ediciones.

Alberdi, J. B. (1956) Derecho Público Provincial. Buenos Aires: Universidad de Buenos Aires.

BARros, M. (2008) Articulación de lógicas y conceptos: el análisis político desde la teoría del discurso post-estructuralista, Pensamento Plural, 3, julho-dezembro, pp. 167178.

BArros, S. (2017). No todo el mundo puede decir la verdad. Foucault, la parrhesía y el populismo. Las Torres de Lucca, 11, julio-diciembre, pp. 251-282.

- (2013a). Pensar la diferencia. Carencia y política en Pierre Clastres. Íconos. Revista de Ciencias Sociales, 47, pp. 121-133.

. (2013b) Despejando la espesura. La distinción entre identificaciones populares y articulaciones políticas populistas. En AbOy CARles, G. BARros, S. y Melo, J., Las brechas del pueblo. Reflexiones sobre identidades populares y populismo (pp. 41-64). Buenos Aires: UNDAV-UNGS.

Bennington, G. (2016). Scatter 1: The Politics of Politics in Foucault, Heidegger, and Derrida, New York: Fordham University Press. 
BlenginO, L. F. (2014). Gobernar en la verdad: democracia y liderazgo a la luz de la problematización foucaultiana de la parrhesía política. El banquete de los dioses, 2(2), pp. 104-124.

Buenfil Burgos, R. N. y Navarrete Cazales, Z. (coords.) (2011). Discursos educativos, identidades y formación profesional. Producciones desde el análisis político de discurso. México: Plaza y Valdés-PAPDI.

Castro, E. (2014). Introducción a Foucault. Buenos Aires: Siglo Veintiuno Editores.

Clastres, P. (2009). Arqueología de la violencia. Buenos Aires: Fondo de Cultura Económica (FCE).

. (2008). La sociedad contra el Estado. La Plata: Terramar. . (1987). Investigaciones en antropología política. México: Gedisa.

Dyrberg, T. B. (2014) Foucault on the Politics of Parrhesia. New York-London: Palgrave Macmillan.

Foucault, M. (2017). Discurso y verdad: Conferencias sobre el coraje de decirlo todo. Grenoble, 1982 / Berkeley, 1983. Buenos Aires: Siglo Veintiuno Editores. . (2010). El coraje de verdad: el gobierno de sí y de los otros II. Curso en el Collège de France (1983-1984). Buenos Aires: FCE.

- (2009). El gobierno de sí y de los otros: curso en el Collège de France: 1982-1983. Buenos Aires: FCE.

- (2007). Nacimiento de la biopolítica: curso en el Collège de France: 1978-1979. Buenos Aires: FCE.

- (1999). Estética, ética y hermenéutica. Obras esenciales, Volumen III. Barcelona: Paidós.

. (1977). Poderes y estrategias. En Microfísica del poder (pp. 163-174). Madrid: Ediciones de La Piqueta.

Glynos, J. y Howarth, D. (2007). Logics of Critical Explanation in Social and Political Theory. London: Routledge.

Kalyvas, A. (2008). Democracy and the Politics of the Extraordinary: Max Weber, Carl Schmitt, and Hannah Arendt. Cambridge: Cambridge University Press.

LACLAU, E. (2005). La razón populista. Buenos Aires: FCE. . (1990). New Reflections on the Revolution of Our Time. London: Verso. y Mouffe, C. (1985). Hegemony and Socialist Strategy. Towards a Radical Democratic Politics. London: Verso. 
Lefort, C. (2007). La obra de Clastres. En Abensour, M. (comp.), El espíritu de las leyes salvajes: Pierre Clastres o una nueva antropología política (pp. 279-314). Buenos Aires: Del Sol. . (1990). La invención democrática. Buenos Aires: Nueva Visión. . (1988). ¿Permanece lo teológico político? Buenos Aires: Librería Hachette.

Loraux, N. (2007). Notas sobre el Uno, el dos y lo múltiple. En Miguel Abensour (comp.), El espíritu de las leyes salvajes: Pierre Clastres o una nueva antropología política (pp. 243-264). Buenos Aires: Del Sol.

LuXON, L. (2004). Truthfulness, risk, and trust in the late lectures of Michel Foucault. Inquiry, 47, pp. 464-489.

Moyn, S. (2013). Claude Lefort, political anthropology, and symbolic division. En Plot, M. (Ed.), Claude Lefort. Thinker of the Political (pp. 51-70). London, New York: Palgrave Macmillan.

Norval, A. (2012). 'Writing a Name in the Sky': Rancière, Cavell, and the possibility of egalitarian inscription. American Political Science Review, 106(4), pp. 810-826. . (2006). Democratic Identification: A Wittgensteinian Approach. Political Theory, 34(2), pp. 229-255.

PADIlla, C. y Ruiz Del Ferrier, C. (2015). Entrevista al Dr. Gerardo Aboy Carlés. Revista Estado y Políticas Públicas, 4, pp. 183-192.

Plot, M. (2015). ¿Permanencia de lo estético-político? Coexistencia y conflicto de regímenes políticos en Lefort, Rancière y Merleau-Ponty. En GambarotTA, E. Borovinsky, T. y PlOt, M. (coords.) Estética, política, dialéctica: el debate contemporáneo (pp. 33-54). Buenos Aires: Prometeo Libros.

RAFFIn, M. (2018). La noción de política en la filosofía de Michel Foucault. Hermenéutica intercultural. Revista de filosofía, 29, pp. 29-59.

RANCIÈRE, J. (2019). Los bordes de la ficción. Buenos Aires: Edhasa. . (2014). El reparto de lo sensible: estética y política. Buenos Aires: Prometeo Libros. - (2011). El malestar en la estética. Buenos Aires: Capital Intelectual. . (2006). El desacuerdo. Política y filosofía. Buenos Aires: Nueva Visión. . (2004). Who is the subject of the rights of man. The South Atlantic Quarterly, 103(2-3), pp. 297-310. . (2003). El maestro ignorante. Barcelona: Laertes.

TiBle, J. (2013). Marx selvagem. São Paulo: Annablume. 